\title{
Experimental and Simulation Study of Resistive Helical HTS Fault Current Limiters: Quench and Recovery Characteristics
}

\author{
Wenjuan Song, Member, IEEE, Xiaoze Pei, Member, IEEE, Hamoud Alafnan, Jiawen Xi, Student member, IEEE, \\ Xianwu Zeng, Mohammad Yazdani-Asrami, Member, IEEE, Bin Xiang, Zhiyuan Liu
}

\begin{abstract}
Resistive type fault current limiters (SFCLs) have attracted lots of attention from research interests and engineering applications, due to its self-triggering, fast and effective fault current limitation ability. Fast recovery of SFCL after quench is highly attractive, yet still remains challenge when recover with load compared to recovering without load. We investigated the dependence of recovery time of a helical SFCL coil on the ratio of prospective current over critical current. A multilayer simulation model was built in MATLAB ${ }^{\circledR} /$ Simulink to investigate the electro-thermal behavior of SFCL coil during a fault and recovery period, and the model was validated by experimental results. Quench simulations were carried out under different $I_{\text {pros }} / I_{\mathrm{c}}$, ranging from 15 to 119 and in different recovery conditions including recovery with load condition and recovery without load condition, while keeping the fault duration of $100 \mathrm{~ms}$. We observed that the SFCL coil reached $85 \mathrm{~K}$ and $195 \mathrm{~K}$ at the time when the fault was cleared, in the quench tests with $I_{\text {pros }} / I_{\mathrm{c}}=15$ and 119 , respectively. SFCL coil recovered without load in $0.5 \mathrm{~s}$ to $10 \mathrm{~s}$, depending on the ratio of $I_{\text {pros }} / I_{\mathrm{c}}$.
\end{abstract}

Index Terms-Helical SFCL coil, flux flow, quench, recovery.

\section{INTRODUCTION}

Sisin UPERCONDUCTING fault current limiters (SFCLs) are promising applications to suppress the amplitude of fault current once a fault happens in a power system, and reduce the burden of circuit breaker to clear the fault, and hence, protects electrical devices from being damaged [1-3]. Resistive-type SFCLs (RSFCLs) have drawn great attention from researchers and industry applications, thanks to their effective and reliable current limiting capability, compact size, light weight, compact structure [4-6] and low loss with bifilar coil structure [7-9]. These merits are particularly highly required for future electric aircraft.

There are a lot of studies on the current limiting and recovery characteristics of coated superconductors and resistive SFCLs, by the means of experiment and numerical modelling [10-20].

Manuscript receipt and acceptance dates will be inserted here. This work is funded by the UK EPSRC EP/S000720/1, Developing Superconducting Fault Current Limiters (SFCLs) for Distributed Electric Propulsion Aircraft, and the UK Royal Society International Exchanges 2018 Cost Share (China) IECINSFC1181111: Advanced DC fault protection by integration of superconducting fault current limiter (SFCL) with DC circuit breaker. (Corresponding author: Wenjuan Song)

W. Song, X. Pei, H. Alafnan, and J. Xi are with the Department of Electronic \& Electrical Engineering, The University of Bath, Bath, BA2 7AY, U.K. (emails: ws603@bath.ac.uk, $\quad$ x.pei@bath.ac.uk, hfa25@bath.ac.uk, jx526@bath.ac.uk).
Noe et al studied the design and simulation of a $24 \mathrm{kV} / 1 \mathrm{kA} \mathrm{R}$ SFCL in ECCOFLOW project [10]. Tixador et al investigated on improving the properties of REBCO tapes with enhanced electric field limit up to $150 \mathrm{~V} / \mathrm{m}$ in the European Union Project FASTGRID [11]. Song et al conducted system simulation of a $160 \mathrm{kV} / 1 \mathrm{kA}$ R-SFCL in Nan'ao transmission line in China [12]. Xiang et al demonstrated a $10 \mathrm{kV}$ R-SFCL integrated with mechanical circuit breaker. The tests showed that the fault current was limited from $10 \mathrm{kA}$ to $1.42 \mathrm{kA}$, and that it required more than $1 \mathrm{~s}$ for the R-SFCL to recover [14]. Yazdani-Asrami et al investigated heat transfer and recovery characteristic enhancement methods for metal and superconducting tapes under high current pulse, and improved the fault current limiting behavior. The fault withstand time was extended up to $2 \mathrm{~s}$ under load, achieved by coated conductor with solid polymer insulation with designed thickness operated in sub-cooled $65 \mathrm{~K}$ cryogenic environment $[15,16]$.

On the numerical modelling, Roy et al proposed a combined component power law to study the resistivity of superconductor in over-critical current regime [17]. Riva et al did a comprehensive calculation study in the resistivity of REBCO tapes in overcritical regime, by comparing power-law model and overcritical resistivity model [18]. Liang et al proposed and validated a modified $E-J$ power law to simulate the quench behavior of RSFCL [19].

Many publications have investigate the quench and recovery performance of superconducting tapes and R-SFCLs, however, there is a gap in exploring the current limiting and recovery behavior of a helical R-SFCL under high ratio of prospective current $\left(I_{\text {pros }}\right)$ over critical current $\left(I_{\mathrm{c}, \text { coil }}\right)$.

$\mathrm{X}$. Zeng is with the Department of Mechanical Engineering, The University of Bath, Bath, BA2 7AY, U.K. (e-mail: xz2478@ bath.ac.uk).

M. Yazdani-Asrami, is with Department of Electronic and Electrical Engineering, University of Strathclyde, Glasgow, G1 1XW, UK (e-mail: mohammad.yazdani-asrami@strath.ac.uk).

B. Xiang and Z. Liu are with State Key Laboratory of Electrical Insulation and Power, Department of Electric Power Engineering, Xi'an Jiaotong University, China. (e-mail: xiangbin0319@163.com, liuzy@mail.xjtu.edu.cn)

Color versions of one or more of the figures in this paper are available online at http://ieeexplore.ieee.org.

Digital Object Identifier will be inserted here upon acceptance. 
TABLE I

SPECIFICATIONS OF HTS COATED CONDUCTOR

\begin{tabular}{lc}
\hline \hline \multicolumn{1}{c}{ Parameter } & Value \\
\hline Conductor type & AMSC-8602 \\
Conductor width, mm & 12 \\
Thickness of superconducting layer, $\mu \mathrm{m}$ & 1 \\
Thickness of stainless-steel laminate, $\mu \mathrm{m}$ & $75 \times 2$ layers \\
Thickness of substrate, $\mu \mathrm{m}$ & 75 \\
Material of stainless steel & (SUS)316L \\
Material of substrate, & Ni-5at.\%W \\
Minimum critical current $I_{\mathrm{c}, \min } @ 77 \mathrm{~K}, \mathrm{~A}$ & 241 \\
Quench resistance at $92 \mathrm{~K}, \mathrm{~m} \Omega$ & 53 \\
Quench resistance at $300 \mathrm{~K}, \mathrm{~m} \Omega$ & 123 \\
\hline \hline
\end{tabular}

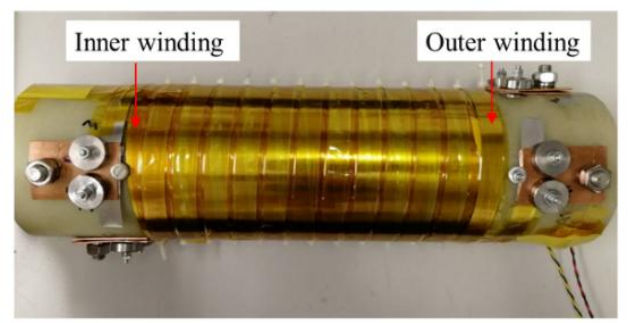

Fig. 1. Prototype of the helical SFCL coil.

In this paper, a helical bifilar coil where inner and outer windings are connected in series was designed and manufactured. The fault limiting characteristics and recovery performance of the SFCL was studied experimentally and simulation using an electro-thermal model in MATLAB/SIMULINK $[18,21]$. The fault tests were conducted up to $I_{\mathrm{pros}}=15 I_{\mathrm{c}, \text { coil }}=3795 \mathrm{~A}$, and simulated case study was carried out under a much higher ratio of $I_{\text {pros }} / I_{\mathrm{c}}$, which is beyond the testing capability of experimental rig.

\section{EXPERIMENTAL METHOD}

Table I lists the specifications of HTS coated conductor for winding the helical bifilar SFCL coil. The coil is composed of one inner winding and one outer winding, and these windings are wound on the same G10 bobbin but in opposite direction. Each winding has one layer, and the pitch length keeps $15.5 \mathrm{~mm}$. Fig. 1 shows the prototype of the SFCL coil. The $I_{c}$, coil was measured at $77 \mathrm{~K}$ and self-field, and it is $251 \mathrm{~A}$. The length of inner and outer windings is 3.5 and $3.7 \mathrm{~m}$, respectively. The overall length of the SFCL coil is $7.2 \mathrm{~m}$, when two winding is connected in series. A detailed specification of the SFCL coil can be found in our previous work [22].

All the fault tests were carried out in liquid nitrogen bath at $77 \mathrm{~K}$. Fig. 2 shows the schematic of the quench test circuit. $R_{\text {load }}$ is a power resistor. $R_{1}$ is line impedance of the circuit. $R_{2}$ is a power resistor which is used to control the current amplitude below 3 A during recovery, to simulate the recover mode without load. S1 is to control the main circuit and switching the two recovery modes. S2 is to emulate the fault by short circuit the load resistor. The current is measured using a current transducer. Trigger circuit produces the trigger signal for S1 and S2 at specific time. There are three stages in each quench test: 1) Normal operation when S1 is closed and S2 is open; 2) Fault period

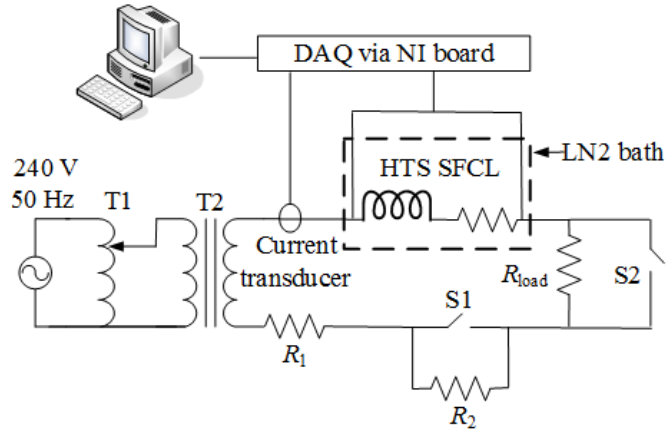

Fig. 2. Schematic diagram of the quench test circuit.

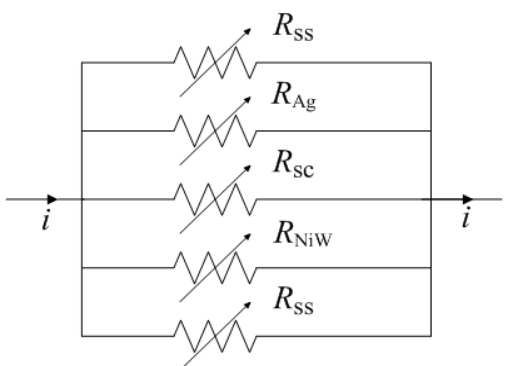

Fig. 3. Multilayer model for SFCL coil.

when S1 and S2 are both open; 3) Recovery period, and there are two recovery mode used in this work:

a. Recover with load mode: S1 is closed and S2 is open (nominal current flows through SFCL in the recovery period);

b. Recover without load mode: S1 and S2 are both open (very low current flows through SFCL in recovery period)

The quench test system can be set up with any time duration for normal, fault, and recovery period. The fundamental frequency of the current is $50 \mathrm{~Hz}$ in all experiments [22].

\section{NUMERICAL METHOD}

Previous studies have reported simulation methods for SFCL using Matlab/Simulink [23, 24] and finite element method in COMSOL $[18,21,25,26]$. In this paper, a multilayer electrothermal coupled simulation model was built in MATLAB ${ }^{\circledR} /$ Simulink to study the electrical and thermal behavior of the SFCL coil during quench [17, 18, 27, 28]. Two stainless steel (SS) layers, silver layer, superconducting layer, and substrate NiW layer were considered in the model. Fig. 3 shows the multilayer model for the SFCL. The resistance of each layer varied with the temperature of SFCL coil, and the current was shared in these layers following the Ohm's law. We assumed the temperature of all layers of SFCL coil remains the same.

The resistivity of superconducting layer is derived from the $E$-J Power law [29], as described in (1),

$$
\rho_{\mathrm{SC}}=\frac{E_{\mathrm{c}}}{J_{\mathrm{c}}(T)}\left(\frac{|J|}{J_{\mathrm{c}}(T)}\right)^{(n-1)} \quad T<T_{\mathrm{c}} \text { and } J>J_{\mathrm{c}}
$$

where $E_{\mathrm{c}}=1 \mu \mathrm{V} / \mathrm{cm}$.

When the SFCL coil operates in normal operation, nearly zero resistivity exists in superconducting layer and all the curent passes through this layer. When a fault happens, fault current is higher than the critical current of the SFCL coil, leading to increase of the resistivity of superconducting layer [30, 31]. 
The critical current density $J_{\mathrm{c}}$ of superconducting coil is dependent on external magnetic field and temperature [32, 33]. Here, the dependency of $J_{\mathrm{c}}$ on temperature was considered only due to the strong electro-thermal behavior of the quench process, and it is shown by Eq. (2).

$$
J_{\mathrm{c}}(T)=J_{\mathrm{c} 0}\left(\frac{\left(T_{\mathrm{c}}-T(t)\right)^{a}}{\left(T_{\mathrm{c}}-T_{0}\right)^{a}}\right) \quad T_{0}<T<T_{\mathrm{c}}
$$

where $J_{\mathrm{c} 0}=2.09 \times 10^{9} \mathrm{~A} / \mathrm{m}^{2}$ is the critical current density at the initial temperature $T_{0}=77 \mathrm{~K}$, the boiling point of $\mathrm{LN}_{2} . T_{\mathrm{c}}=92$ $\mathrm{K}$ is the critical temperature, and $\alpha$ is the density exponent, 1.5 was used here [34]. When the resistivity of superconducting layer increases, the current starts to flow through other layers depends on their resistances.

The resistivity of the silver, NiW and stainless-steel layers in terms to temperature are sourced from [35-37], respectively. Each layer's resistance is calculated based on Eq. (3):

$$
R_{k}=\rho_{k} l / S_{k}
$$

where $k$ represents different layer of silver, $\mathrm{NiW}$, stainless steel and superconducting layer; $l$ and $S$ are the length and cross-section area of each layer; and $\rho$ is each layer's resistivity as sourced from [35-37]. The temperature of the superconductor is obtained by Eq. (4):

$$
T(t)=T_{0}+\frac{1}{C_{\mathrm{p}}} \int_{0}^{t} Q_{\mathrm{sc}}(t) d t
$$

where $C_{\mathrm{p}}$ is the equivalent heat capacity of the coil considering the superconductor layer, stainless steel layer, silver layer and substrate NiW layer [38]; $Q_{\mathrm{sc}}$ corresponds to the net power in the SFCL coil and it can be calculated by Eq. (5)-(7),

$$
\begin{gathered}
Q_{\mathrm{sc}}(t)=P_{\text {diss }}(t)-P_{\text {cooling }}(t) \\
P_{\text {diss }}(t)=\sum_{k=1}^{4} i(t)_{k}^{2} \times R_{k}(t) \\
P_{\text {cooling }}(t)=h A\left(T(t)-T_{0}\right)
\end{gathered}
$$

where $P_{\text {diss }}$ and $P_{\text {cooling }}$ are the power absorbed in SFCL coil from the fault and the power which was taken away from SFCL coil by the coolant. $A$ is the surface area of the SFCL covered by the $\mathrm{LN}_{2}$ coolant (50\% of SFCL coil's surface area was considered here); $h$ is the heat transfer coefficient, which is primarily based on the temperature difference $\Delta T$ between the outer surface of the tape and the coolant $\mathrm{LN}_{2}$. In this study, the transfer coefficient, $h$, is adopted from the literatures in $[23,24]$.

\section{RESUltS AND ANALYSIS}

\section{A. Validation of the Simulation Model}

Fig. 4 compares the simulated and the measured current in the quench test with $I_{\text {pros }}=15 I_{\mathrm{c} \text {, coil. }}$. In Fig. 4(a), the simulated and calculated $I_{\text {pros. }}$ show a good agreement with each other. In the test, the $I_{\text {pros }}$ was limited to 537.4 A in the first half cycle, which corresponds to $14.2 \%$ of $I_{\text {pros. }}$. It is observed that the simulated limited fault current agrees with the measured ones in the fault period. Fig. 4(b) reports the circuit current in three stages of the same quench test, particularly, by a smaller current scale.
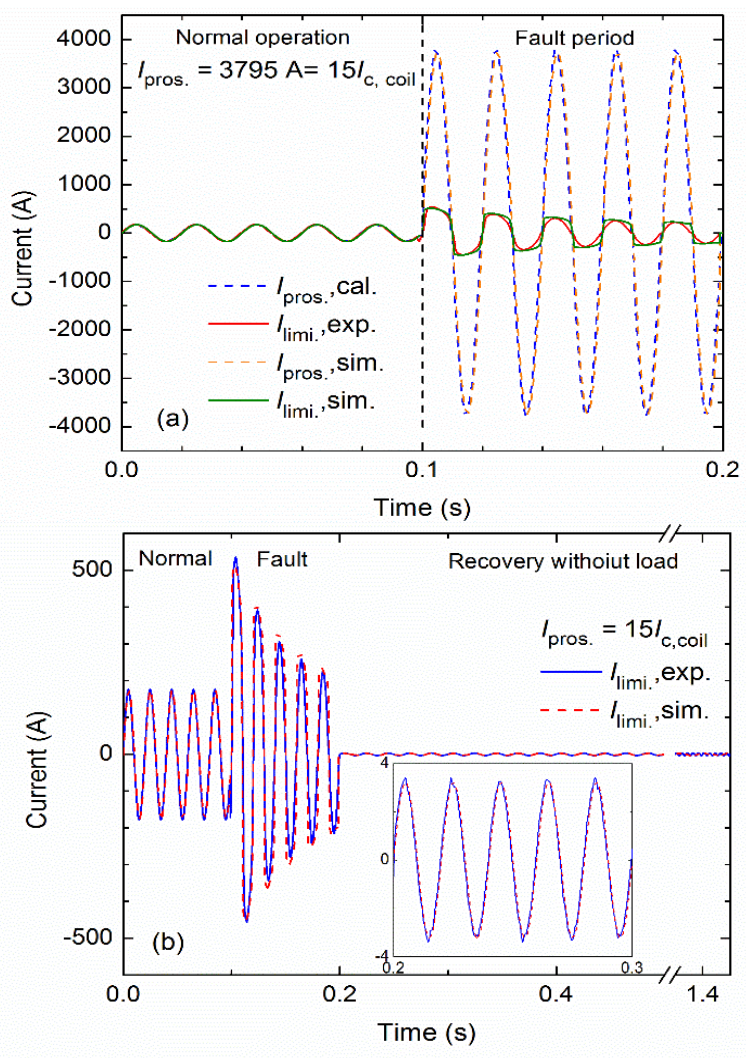

Fig. 4. Comparison of simulated and measured current results when $I_{\text {pros }}=3795$ A. (a) in the stages of normal and fault period (b) in three stages, especially in recovery period.

The measured recovery current is $3.2 \mathrm{~A}$, and the simulated recovery current aligns with the measured one. The agreement between measured and simulated results validates the accuracy of simulation model.

\section{B. Measured Voltages under Two Recovery Modes}

Fig. 5(a) and (b) report and compare the measured voltage of inner winding and outer winding in the same quench tests when $I_{\text {pros }}=15 I_{\mathrm{c} \text {, coil }}$, but under different recovery conditions, one for recovery with load, and another for recovery without load.

As seen in the fault period from both Fig. 5(a) and 5(b), nearly the same voltage drop, $12.5 \mathrm{~V}$, appears on both inner and outer windings of SFCL coil in the first half cycle after fault occurs. It is worthy to note that equal current flows in both windings. With the fault continues, the inner winding gradually occurs larger voltage drop, as compared to outer winding. This is mainly due to the different heat transfer environment of these two windings, and the inner winding has less cooling area which contacts with the $\mathrm{LN}_{2}$ coolant [16].

In terms of the recovery behavior of SFCL coil in the two conditions, Fig. 5(a) and (b) show obviously different trend. In Fig. 5(a), the recovery current is close to the nominal current, around $175 \mathrm{~A}$, and it is observed that around $7 \mathrm{~V}$ and $6 \mathrm{~V}$ voltage drop remains in the inner windings and outer winding after the fault clearance. With the recovery time continues, the voltage in the inner winding keeps increasing, whilst the voltage in outer winding starts to decrease. This is due to the different heat 


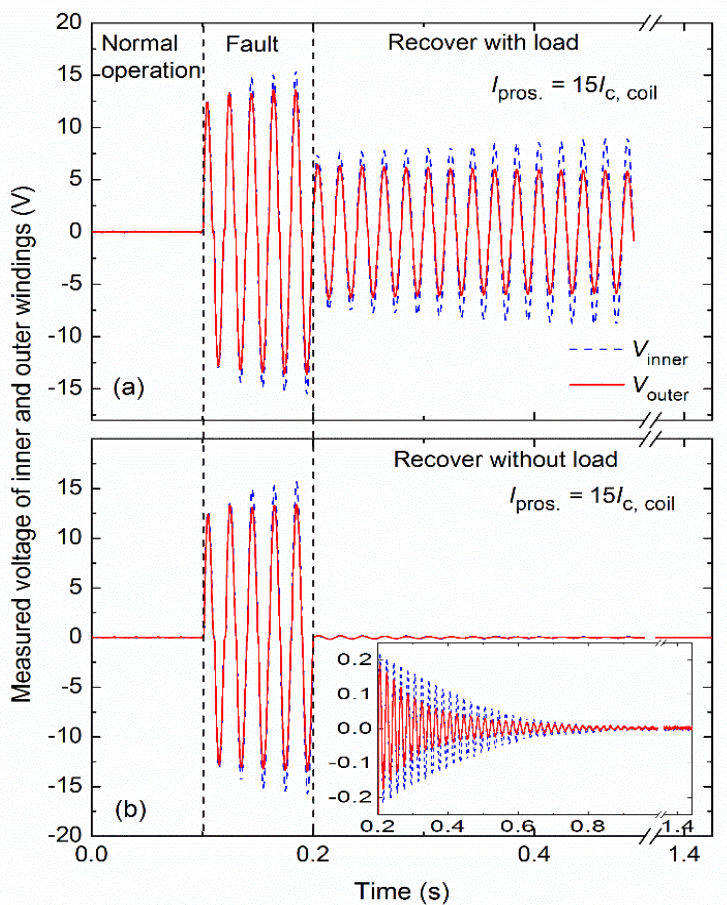

Fig. 5. Measured voltages of SFCL coil during three stages under two recovery modes, when $I_{\text {pros }}=3795$ A. (a) Recover with load (b) Recover without load.

transfer environment, where the outer winding has half of its surface been exposed to $\mathrm{LN}_{2}$. At $0.5 \mathrm{~s}$, the voltage difference between two windings reach to $3 \mathrm{~V}$. To protect the SFCL coil from burn out, the recovery with load only continues for 300 $\mathrm{ms}$. It is revealed from the results that it is quite challenging to get this helical SFCL coil recovered with load, particularly, for the inner winding. It also highlights the necessity of ensuring proper heat transfer for the inner winding.

In Fig. 5(b), the peak value of recovery current is only $3.5 \mathrm{~A}$. The voltage in both windings immediately decreases to around $0.2 \mathrm{~V}$, after the fault has been cleared, and the winding voltage quickly reaches to near zero within $0.8 \mathrm{~s}$, as seen from the enlarged figure inside Fig. 5(b).

\section{Temperature of SFCL and Current Distribution}

Simulated temperature of the helical SFCL coil during the quench test with $I_{\text {pros }}=3795$ A under recovery without load mode is shown in Fig. 6. Items (1), (2), and (3) represent three stages of the quench test. Once the quench happens, the temperature of SFCL coil quickly rises from $77 \mathrm{~K}$ to $85 \mathrm{~K}$ at the end of fault period, which is lower than the critical temperature of SFCL coil, $92 \mathrm{~K}$. It is found that the temperature of SFCL does not increase linearly but shows a wave shape. It is found that the SFCL coil returned to $78 \mathrm{~K}$ within $0.8 \mathrm{~s}$ after the fault clearance. This aligns with the measured results in Fig. 5(b).

Fig. 7 shows the simulated current distribution in different layers of SFCL coil during the quench test with $I_{\text {pros }}=3795$ A and recovery without load mode. During normal operation, all current flow through superconducting layer due to the smallest resistance. During fault period, the majority of the current flows through superconducting layer and some current flows in silver

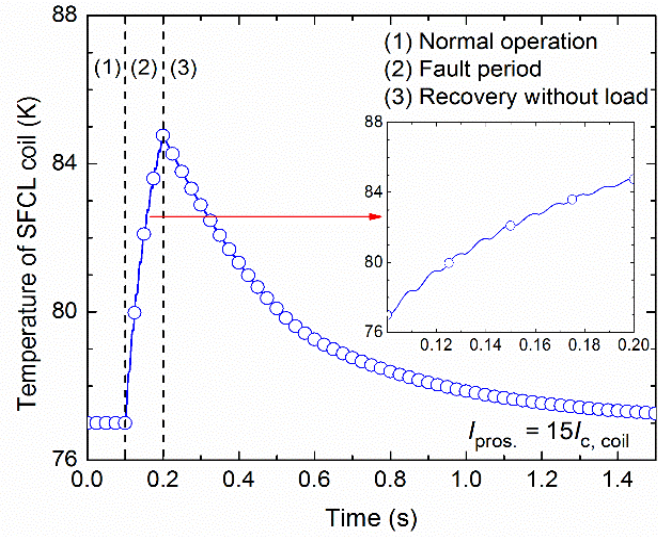

Fig. 6. Simulated temperature of SFCL coil during the quench test when $I_{\text {pros }}=$ 3795 A, where the SFCL was recovered without load.

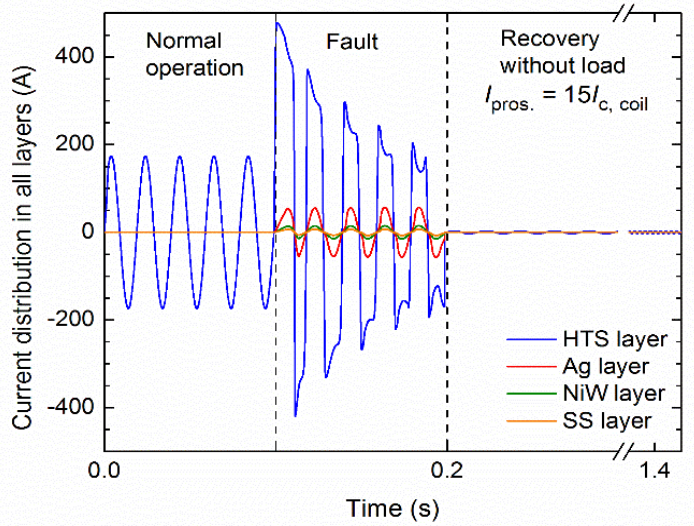

Fig. 7. Simulated current distribution among all layers of SFCL coil in the quench test with recovery without load mode, when $I_{\text {pros }}=3795 \mathrm{~A}$.

layer and NiW layer as well. It shows that SFCL coil enters the flux flow mode and the resistance in the superconducting layer of the SFCL coil increases to a level comparable to other layers. The current distribution agrees with the fact that maximum temperature of SFCL coil during the fault is less than its critical temperature, as shown in Fig. 6. Interestingly, it is observed that the current flowing in superconducting layer did not behave as a sinusoidal waveform, due to a dynamic heating up in flux flow mode of superconducting layer, and this roughly agrees with the temperature change of SFCL in fault cycles. Once the fault happens, R-SFCL immediately enters the flux flow mode. The current starts to transfer to other layers following the Ohm's law. When the current in superconducting layer reduces, the resistivity in HTS layer decreases. And then more current will flow through HTS layer again. It should be pointed out that the voltage of the test system is low and a small resistance from RSFCL can quickly reduce the fault current while maintaining a low temperature.

\section{Simulated Results at Higher $I_{\text {pros }} / I_{\mathrm{c} \text {, coil }}$}

Fig. 8(a) and (b) report the current in the main circuit and current distribution in different layers of SFCL coil during the quench test with a higher $I_{\mathrm{pros}}=119 I_{\mathrm{c} \text {, coil }}$, and under recovery without load mode. In Fig. 8(a), the current in normal operation is $175 \mathrm{~A}$, the same as the quench test with $I_{\text {pros }}=15 I_{\mathrm{c} \text {, coil. }}$. The 


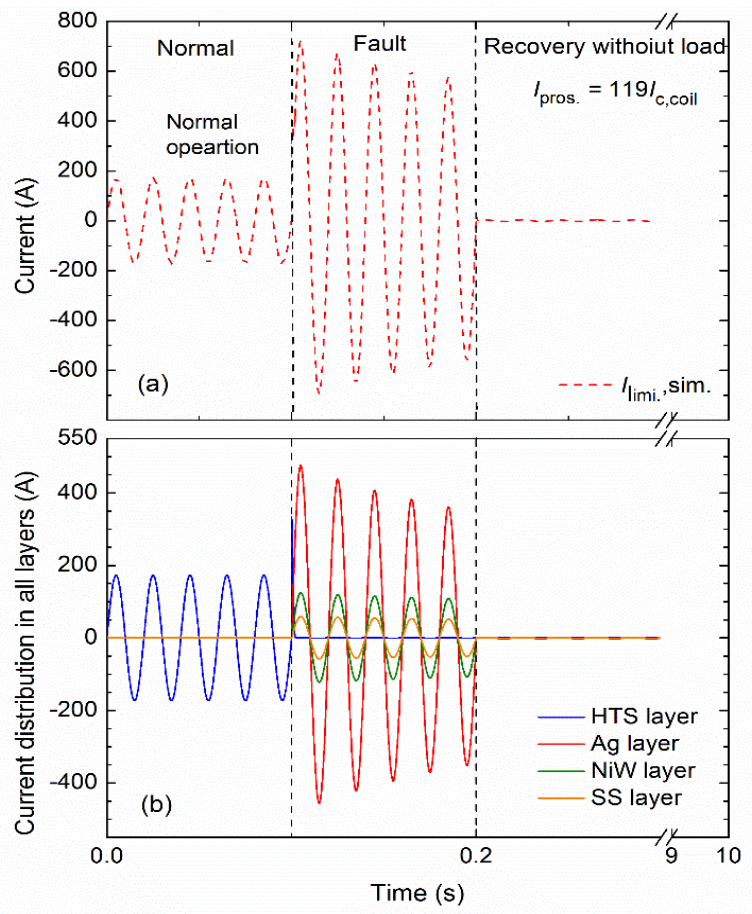

Fig. 8. Simulated current distribution among all layers of SFCL coil in the quench test with recovery without load mode, when $I_{\text {pros }}=119 I_{\mathrm{c} \text {, coil }}$.

prospective fault current was limited to $700 \mathrm{~A}$ in the first half cycle after the fault occurs, which is only $3 \%$ of $I_{\text {pros }}$.

As seen from Fig. 8(b), all current flows in superconducting layer during normal operation; when the fault happens, nearly all current shifts out from superconducting layer, due to high quench resistance caused by temperature rise. It is observed that most current flows through silver layer, and small proportional current goes through NiW layer and stainless-steel layer.

Fig. 9 plots the SFCL coil temperature in the quench test under recovery without load mode, at a higher $I_{\text {pros }}=119 I_{c \text {, coil }}$. As shown in the enlarged figure, SFCL coil temperature quickly rises and it reaches $195 \mathrm{~K}$ when the fault is cleared. It takes almost $10 \mathrm{~s}$ for the SFCL coil to recover to $77 \mathrm{~K}$. It also indicates that when the temperature of SFCL coil is close to $77 \mathrm{~K}$, the heat transfer gets quite slow.

\section{E. Recovery Time at Different $I_{\text {pros }} / I_{\mathrm{c}, \text { coil }}$}

Fig. 10 plots the recovery time of the helical SFCL coil at different $I_{\mathrm{pros}} / I_{\mathrm{c} \text {, coil }}$ value. With the increase of $I_{\text {pros }} / I_{\mathrm{c} \text {, coil }}$ value, the recovery time for the SFCL coil also increases. When $I_{\text {pros }}$ $/ I_{\mathrm{c} \text {, coil }}<5$, SFCL coil can recover immediately after the fault clearance. When $5<I_{\text {pros }} / I_{\mathrm{c} \text {, coil }}<8$, the recovery time of SFCL

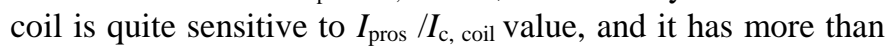
two orders of magnitude change in this range. When $I_{\text {pros }} / I_{\mathrm{c} \text {, coil }}>$ 8 , the recovery time increases accordingly.

\section{CONCLUSIONS}

Experimental tests were carried out to characterize the quench and recovery behavior of a helical SFCL coil under two recovery conditions, with load and without load. A multilayer

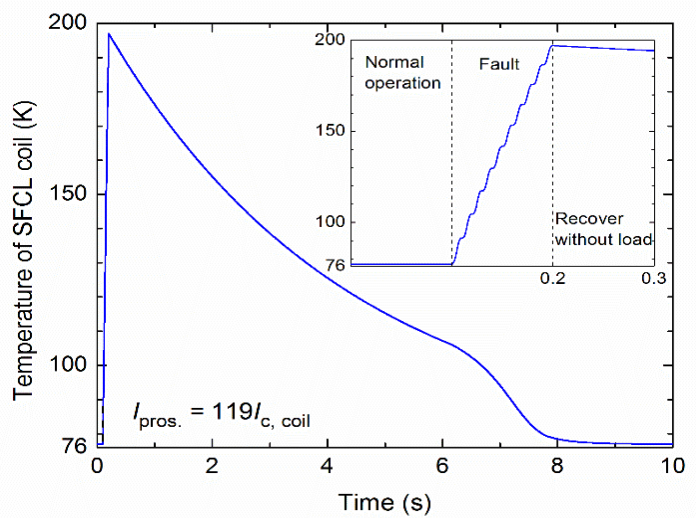

Fig. 9. Temperature change of SFCL coil during the quench test with recovery without load mode, when $I_{\text {pros }}=119 I_{\mathrm{c}, \text { coil }}$.

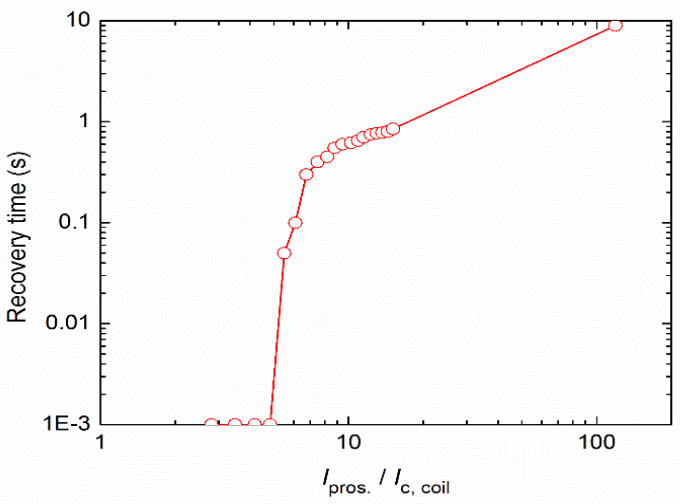

Fig. 10. Recovery time for SFCL coil at different $I_{\text {pros }} / I_{\mathrm{c} \text {, coil }}$ value.

electro-thermal simulation model was built in $\mathrm{MATLAB}^{\circledR} / \mathrm{Sim}$ ulink and validated by the agreement with experimental results.

When the ratio of prospective current to coil critical current, $I_{\text {pros }} / I_{\mathrm{c}}$ coil, is smaller than 8 , the SFCL coil can recover within $0.5 \mathrm{~s}$ without load. The recovery time could be further reduced when the windings are fully exposed to liquid nitrogen.

When $I_{\text {pros }} / I_{\mathrm{c}}$ coil is 15 , the SFCL coil reaches $85 \mathrm{~K}$ and it is still in flux flow mode. The most of current flows in the HTS layer but starts to transfer to other metallic layers.

When $I_{\text {pros }} / I_{\mathrm{c}}$ coil is 119 , the $S F C L$ coil reaches $195 \mathrm{~K}$, indicating a fully quench occurs. Based on the simulation model, most of the current is observed in the silver layer and almost no current flows in the HTS layer.

The recovery time of the SFCL coil increases with the increase of $I_{\text {pros }} / I_{\mathrm{c}}$ coil value. In order to reduce the recovery time, two methods can be implemented to improve the cooling: firstly, design the SFCL winding with lower $I_{\text {pros }} / I_{\mathrm{c}}$ coil value; Secondly, improve the heat transfer performance of SFCLs in all stages, especially nucleate boiling regime, Thirdly, using the subcooled liquid nitrogen between $65 \mathrm{~K}$ and $77 \mathrm{~K}$.

We plan to investigate and compare different resistivity models for the superconductors in the flux flow mode in the future. Furthermore, a study to explore the influence of the cooling curve on the recovery of SFCL will be investigated.

\section{ACKNOWLEDGMENT}

The authors would like to thank Mr. Michael Linham for preparing coil former and providing practical support. 


\section{REFERENCES}

[1] B. Xiang et al., "A CO2/O2 mixed gas DC circuit breaker with superconducting fault current-limiting technology," IEEE Transactions on Power Delivery, vol. 35, no. 6, pp. 1960-1967, 2019.

[2] J.-G. Lee, U. A. Khan, H.-Y. Lee, and B.-W. Lee, "Impact of SFCL on the four types of HVDC circuit breakers by simulation," IEEE transactions on applied superconductivity, vol. 26, no. 4, pp. 1-6, 2016, Art. no. 125011.

[3] B. Xiang et al., "DC interrupting with self-excited oscillation based on the superconducting current-limiting technology," IEEE Transactions on Power Delivery, vol. 33, no. 1, pp. 529-536, 2017.

[4] M. Noe and M. Steurer, "High-temperature superconductor fault current limiters: concepts, applications, and development status," Superconductor Science and Technology, vol. 20, no. 3, pp. R15-R29, 2007.

[5] A. Morandi, "State of the art of superconducting fault current limiters and their application to the electric power system," Physica $C$ : Superconductivity, vol. 484, pp. 242-247, 2013.

[6] B. Xiang, "Study on the parameter requirements for resistive -type superconducting fault current limiters combined with mechanical DC circuit breakers in hybrid AC/DC transmission grids," IEEE Transactions on Power Delivery, vol. 35, no. 6, 2020.

[7] F. Gomory, J. Souc, and M. Vojenciak, "AC transport loss of coated conductors in anti-parallel arrangement," IEEE Transactions on Applied Superconductivity, vol. 21, no. 3, pp. 3307-3310, 2010.

[8] W. Song, Z. Jiang, M. Staines, R. A. Badcock, and J. Fang, "Experimental and numerical transport AC losses in a four-strand Roebel cable bifilar stack," Superconductor Science and Technology, vol. 31, no. 11, 2018, Art. no. 115001

[9] W. Song et al., "AC losses in noninductive SFCL solenoidal coils wound by parallel conductors," IEEE Transactions on Applied Superconductivity, vol. 30 , no. 8, pp. 1-9, 2020.

[10] M. Noe, A. Hobl, P. Tixador, L. Martini, and B. Dutoit, "Conceptual design of a $24 \mathrm{kV}, 1 \mathrm{kA}$ resistive superconducting fault current limiter," IEEE Transactions on Applied Superconductivity, vol. 22, no. 3, 2011, Art. no. 5600304

[11] P. Tixador et al., "Status of the European Union project FASTGRID," IEEE Transactions on Applied Superconductivity, vol. 29, no. 5, pp. 1-5, 2019.

[12] M. Song et al., "The parameter design and system simulation of 160kV/1-kA resistive-type superconducting DC fault current limiter," IEEE Transactions on Applied Superconductivity, vol. 29, no. 5, pp. 1-6, 2019.

[13] B. Xiang et al., "Study on the parameter requirements for resistive-type superconducting fault current limiters combined with mechanical DC circuit breakers in hybrid AC/DC transmission grids," IEEE Transactions on Power Delivery, vol. 35, no. 6, 2020

[14] B. Xiang, L. Gao, Z. Liu, Y. Geng, and J. Wang, "Short-circuit fault current-limiting characteristics of a resistive-type superconducting fault current limiter in DC grids," Superconductor Science and Technology, vol. 33, no. 2, 2020, Art. no. 024005 .

[15] M. Yazdani-Asrami et al., "Fault current limiting HTS transformer with extended fault withstand time," Superconductor Science and Technology, vol. 32, no. 3, 2019, Art. no. 035006.

[16] M. Yazdani-Asrami, M. Staines, G. Sidorov, and A. Eicher, "Heat transfer and recovery performance enhancement of metal and superconducting tapes under high current pulses for improving fault current-limiting behavior of HTS transformers," Superconductor Science and Technology, vol. 33, no. 9, 2020, Art. no. 095014

[17] F. Roy, B. Dutoit, F. Grilli, and F. Sirois, "Magneto-thermal modeling of second-generation HTS for resistive fault current limiter design purposes," IEEE Transactions on Applied Superconductivity, vol. 18, no. 1, pp. 29-35, 2008

[18] N. Riva, F. Sirois, C. Lacroix, W. T. B. de Sousa, B. Dutoit, and F. Grilli, "Resistivity of REBCO tapes in overcritical current regime: impact on superconducting fault current limiter modeling," Superconductor Science and Technology, vol. 33, no. 11, 2020, Art. no. 114008 .

[19] F. Liang, W. Yuan, C. A. Baldan, M. Zhang, and J. S. Lamas, "Modeling and experiment of the current limiting performance of a resistive superconducting fault current limiter in the experimental system," Journal of Superconductivity and Novel Magnetism, vol. 28, no. 9, pp. 2669-2681, 2015.

[20] X. Pei, Superconducting fault current limiter with integrated vacuum interrupter. The University of Manchester (United Kingdom), 2012.

[21] N. Riva, S. Richard, F. Sirois, C. Lacroix, B. Dutoit, and F. Grilli, "Overcritical current resistivity of YBCO-coated conductors through combination of PCM and finite-element analysis," IEEE Transactions on Applied Superconductivity, vol. 29, no. 5, pp. 1-5, 2019.

[22] W. Song, X. Pei, J. Xi, and X. Zeng, "A Novel Helical Superconducting Fault Current Limiter for Electric Propulsion Aircraft," IEEE Transactions on Transportation Electrification, 2020.

[23] W. De Sousa, A. Polasek, R. Dias, C. Matt, and R. de Andrade Jr, "Thermal-electrical analogy for simulations of superconducting fault current limiters," Cryogenics, vol. 62, pp. 97-109, 2014.

[24] W. De Sousa, A. Polasek, C. Matt, and R. de Andrade, "Recovery of superconducting state in an R-SCFCL MCP-BSCCO-2212 assembly," IEEE Transactions on Applied Superconductivity, vol. 23, no. 1, 2013, Art. no. 5601407.

[25] B. Shen, F. Grilli, and T. Coombs, "Overview of H-formulation: A versatile tool for modeling electromagnetics in high-temperature superconductor applications," IEEE access, vol. 8, pp. 100403-100414, 2020

[26] B. Shen et al., "Investigation on power dissipation in the saturated ironcore superconducting fault current limiter," IEEE Transactions on Applied Superconductivity, vol. 29, no. 2, pp. 1-5, 2018.

[27] K. Nam, C. Lee, D. K. Park, T. K. Ko, and B.-Y. Seok, "Thermal and electrical analysis of coated conductor under AC over-current," IEEE Transactions on Applied Superconductivity, vol. 17, no. 2, pp. 1923-1926, 2007.

[28] H. Alafnan, X. Zeng, X. Pei, M. Khedr, M. Zhang, and W. Yuan, "Analysing faults and SFCL response in electric aircraft," in Journal of Physics: Conference Series, 2020, vol. 1559, no. 1: IOP Publishing.

[29] S. Li, D.-X. Chen, and J. Fang, "Transport ac losses of a secondgeneration HTS tape with a ferromagnetic substrate and conducting stabilizer," Superconductor Science and Technology, vol. 28, no. 12, 2015, Art. no. 125011.

[30] Y. Wang, W. K. Chan, and J. Schwartz, "Self-protection mechanisms in no-insulation (RE) $\mathrm{Ba} 2 \mathrm{Cu} 3 \mathrm{O}$ x high temperature superconductor pancake coils," Superconductor Science and Technology, vol. 29, no. 4, 2016, Art. no. 045007.

[31] Y. Wang et al., "No-insulation high temperature superconductor winding technique for electrical aircraft propulsion," IEEE Transactions on Transportation Electrification, 2020.

[32] M. Yazdani-Asrami, S. A. Gholamian, S. M. Mirimani, and J. Adabi, "Investigation on effect of magnetic field dependency coefficient of critical current density on the AC magnetizing loss in HTS tapes exposed to external field," Journal of Superconductivity and Novel Magnetism, vol. 31, no. 12, pp. 3899-3910, 2018.

[33] M. Yazdani-Asrami, S. A. Gholamian, S. M. Mirimani, and J. Adabi, "Calculation of AC magnetizing loss of ReBCO superconducting tapes subjected to applied distorted magnetic fields," Journal of Superconductivity and Novel Magnetism, vol. 31, no. 12, pp. 3875-3888, 2018.

[34] M. Elshiekh et al., "Effectiveness of superconducting fault current limiting transformers in power systems," IEEE Transactions on Applied Superconductivity, vol. 28, no. 3, pp. 1-7, 2018.

[35] R. A. Matula, "Electrical resistivity of copper, gold, palladium, and silver," Journal of Physical and Chemical Reference Data, vol. 8, no. 4, pp. 1147-1298, 1979.

[36] N. Bagrets, M. Schwarz, C. Barth, and K.-P. Weiss, "Thermal conductivity of materials used for preparation of the hybrid layered conductors based on high temperature superconductors," in AIP Conference Proceedings, 2012, vol. 1435, no. 1, pp. 281-285: American Institute of Physics.

[37] C. Y. Ho and T. Chu, "Electrical resistivity and thermal conductivity of nine selected AISI stainless steels," in "CINDAS Report 45," American Iron and Steel Institute, Washington, DC, 1977.

[38] M. Elshiekh, "Increasing wind energy integration into power grids using multifunctional superconducting devices design," University of Bath, 2020. 